\title{
Forgiveness, Gratitude, and Happiness among College Students
}

\author{
Triantoro Safaria \\ Magister of Professional Psychology, Universitas Ahmad Dahlan, Yogyakarta, Indonesia
}

\begin{tabular}{l} 
Article Info \\
\hline Article history: \\
Received Oct 31, 2014 \\
Revised Nov 20, 2014 \\
Accepted Nov 26, 2014 \\
\hline
\end{tabular}

\section{Keyword:}

College student

Forgiveness

Gratitude

Happiness

\begin{abstract}
Wellbeing is the ultimate goal for everyone, not only for adolescence. Present study explored the relationships between gratitude and forgiveness with happiness among college student. A total of 81 undergarduate psychology students were recruited in this study from a private university in Jogjakarta. 29.6\% (24) of the sample were males and $70.4 \%$ (57) were females. Regression analysis was used to predict the relationship between all variables. Regression analysis predict relationship between gratitude and forgiveness with happiness, explaining $28.9 \%$ of the variance (Adjusted $\mathrm{R}^{2}=$ $0.289)$. Gratitude give the biggest contribution to happiness $(\beta=.536 \mathrm{p}=$ .000 ), but forgiveness has no significance relationship to happiness $(\beta=.078$, $\mathrm{p}=.414$ ). This result means that gratitude is an important factor contributes to happiness among undergraduate student in this sample.
\end{abstract}

Copyright (C) 2014 Institute of Advanced Engineering and Science. All rights reserved.

Corresponding Author:

Triantoro Safaria, Magister of Professional Psychology, Universitas Ahmad Dahlan, Jalan Kapas no.9, Semaki, Umbulharjo, Yogyakarta, Indonesia Email: safaria_diy@yahoo.com

\section{INTRODUCTION}

Previous research has found that happiness has some positive impact on the person. Person who are happy have better positive energy than unhappy. Person who are happy tend to be more energetic, passionate and vibrant as compared to the less happy individual [1]-[3]. Happiness is also associated with increased activity [4]. Happiness is also associated with increased engagement and sociability [1],[3].

In addition, person who are happy have more mental resources, than person who are less happy. They are also more creative, attentive (mindfulness), and more optimistic. They also show broader thought and attention, as well as more open to information [4]. In the sample of children who are happy, it was showed that their ability to delay gratification are longer than children who are less happy [5],[6]. Other studies indicate that person who are happy have social support and social involvement greater than unhappy [7]-[9]. Happiness is also positively related to self-esteem [10].

Several factors were found to have a significant relationship with happiness. These factors include forgiveness and gratitude [11]-[13]. Several previous studies have shown that forgiveness contribute to the health and psychological well-being [11],[12],[14],[15]. Forgiveness can also reduce negative emotions, hatred, and revenge intention against the perpetrators [11]. Person who are less able to forgive, indicate greater sympathetic nervous system activation and stress response than the individual who easily forgive [16]. In addition, person who forgiving have better health, and using more positive coping strategies than the less capable to forgive [17], have higher life satisfaction [13] and to reduce the negative effects of resentment that causes excessive stress on the body's reaction [18].

Past research has also demonstrated the contribution gratitude towards happiness. Froh, Yurkewicz, \& Kashdan (2008) [19] found gratitude has a significant positive correlation with positive affect, life satisfaction, optimism, social support, and prosocial behavior. Gratitude also showed a significant negative correlation with physical symptoms, but not with negative affect. Gratitude also shows a strong association 
with emotion proud, hopeful, inspired, forgiveness, and excitement. Wood, Joseph, and Maltby (2009) [20] found gratitude has a positive relationship with autonomy, personal growth, environmental mastery, selfacceptance, purpose in life and positive relationship. The aim of present study is to examine the relationship between forgiveness and gratitude with wellbeing.

\section{HAPPINESS AND FORGIVENESS}

Happiness is an important aspect in the construct subjective wellbeing, sometime happiness becomes synonymous of subjective wellbeing. Subjective wellbeing involves various ways of assessing and experienced person in his life. Subjective wellbeing encompasses more than positive feelings. Tov and Diener (2013) [21] synthesizing of subjective wellbeing consists of three interrelated aspects, namely the frequency of positive affect experiences, infrequent negative affect, and the achievement of life satisfaction. Happiness becomes the most searching goal by individual in one's life as a final result of the achievement of the various wants and needs. Previous research has found that forgiveness and gratitude as two factors that lead to happiness.

Forgiveness is broadly understood as a process of decreasing inter-related resentment-based negative emotions, motivations, and cognition [22]. Forgiveness is a process by which person forgive misbehavior of others, thereby reducing the tendency of person to seek revenge [23]. Forgiveness reduces the tendency of unforgiveness, and it will impact on the decrease of negative emotions such as resentment, hatred and revenge [24].

Further, gratitude is an attitude of accepting and grateful for what the person received in their life [25]. Gratitude is related to an individual's ability to appreciate the simple events in his life. Person who possess this gratitude will tend to appreciate the simple events as a positive event. Gratitude can be present in the form of emotion and affective trait [26],[27]. Gratitude as emotions arise in the form of joy when receiving gifts or benefits, while as grateful disposition it is characterized by general propensity to respond and appreciate with gratitude emotion for the kindness of others in positive experience [26],[28].

\section{RESEARCH METHOD}

\section{Questionnaire}

Happiness. The Oxford Happiness Questionnaire was used after adapting in Indonesian language [29]. A pilot study was conducted to test the validity and reliability of questionnaire before being used to collect data. The consistency internal tests of reliability were carried out using Cronbach alpha, and content validity was assessed using professional judgment. Forward-backward translation method was used to validate the items of questionnaire. Two external experts in the field of psychology were involved in checking items in the questionnaire. The Oxford Happiness Questionnaire has 29 items six-point Likert scale which are answered on a scale of 1 (strongly disagree) to 6 (strongly agree). The example of the items are: "I don't feel particularly pleased with the way I am"; "I am intensely interested in other people"; "I feel that life answered is very rewarding"; "I have very warm feelings towards almost everyone". The Cronbach alpha was .811.

Forgiveness. Transgression-related Interpersonal Motivation Inventory [38] (TRIM; McCullough \& Witvliet, 2002) was used to measure state forgiveness and was translated to Indonesian language. TRIM consists of 12 items, answered on a 1-5 Likert scale from strongly disagree to strongly agree. Forwardbackward translation method was used to validate the items of TRIM. The example of the items are: "I will make him/her pay"; I keep as much distance between us as possible”; "I am going to get even". The Cronbach alpha was .924.

Gratitude. Gratitude Questionnaire 6 (GQ-6) was used to measure the gratitude adjectives (grateful, thankful, and appreciative) among participants. GQ-6 used a 9-point Likert type scale ranging from 1 (inaccurate) to 9 (accurate). Forward-backward translation method was used to validate the items in Indonesian language. The example of items are: "I have so much in life to be thankful for"; "I am grateful to a wide variety of people”; “ When I look at the world, I don't see much to be grateful for". The Cronbach alpha was .803.

\section{Participants}

A total of 81 undergarduate psychology students were recruited into this study from a private university in Jogjakarta, Indonesia. 29.6\% (24) of the sample were males and $70.4 \%$ (57) were females. Regarding the age of participants, $40.7 \%$ (33) of the students in the sample were aged 19 years old, $44.4 \%$ (36) were 20 years old, $6.2 \%$ (5) were 21 years old, $6.2 \%$ (5) were 22 years old, and $2.5 \%$ (2) were 23 years 
old. Regarding the ethnic of participants, $61.7 \%$ of the sample were from Javanese etnic, and $38.3 \%$ of the sample were others (borneo, sundanese, malay).

\section{Data Analysis}

The present study used cross-sectional data. Quantitative data analaysis was performed for the purposes of this study. Descriptive analysis, and regression were applied to analyse the data.

\section{RESULTS AND ANALYSIS}

A Pearson correlation coefficient was conducted to examine the relationship between variables. Table 1 indicates that a moderate positive correlation $(\mathrm{r}=.548, p<.01)$ was found between gratitude and happiness. However, no significant relationships between forgiveness and happiness were found $(r=.160$, $p>.05)$

\begin{tabular}{llcccc}
\multicolumn{6}{c}{ Table 1. Means, Standard Deviations, and Intercorrelations on Four Measures of Creativity } \\
\hline \multicolumn{7}{c}{ Measure } & $M$ & $S D$ & 1 & 2 \\
\hline 1. & Forgiveness & 51.7 & 9.5 & & \\
2. & Gratitude & 41 & 4.9 & .152 & \\
3. & Happiness & 38.7 & 5.3 & .160 & $.548^{* *}$ \\
\hline
\end{tabular}

$$
* p<.05 . * * p<.01
$$

The regression analysis predict relationship between gratitude and forgiveness with happiness, explaining $28.9 \%$ of the variance (Adjusted $R^{2}=0.289$ ). Table 2 indicate that gratitude give the biggest contribution to happiness $(\beta=.536 \mathrm{p}=.000)$, but forgiveness has no significance relationship to happiness $(\beta=$ $.078, \mathrm{p}=.414)$. This result means that gratitude is an important factor contribute to happiness among undergraduate student in this sample.

Table 2. Regression Analysis Summary Forgiveness, Gratitude, and Happiness

\begin{tabular}{llllll}
\hline Variable & $B$ & $S E B$ & $\beta$ & $t$ & $p$ \\
\hline Forgiveness & .044 & .053 & .078 & .822 & .414 \\
Gratitude & .584 & .104 & .536 & 5.618 & .000 \\
\hline
\end{tabular}

Note. Adjusted $R^{2}=.289(N=81, p=.000)$.

The results of this study indicate that gratitude has a role in predicting happiness among college students. These results confirm previous studies [13],[18] (Froh, Yurkewicz, \& Kashdan, 2008; Wood, Joseph, and Maltby, 2009) which shows the role of gratitude in improving wellbeing. Generally, grateful people experience more life satisfaction, optimism, vitality, and less depression and envy. Grateful people also endorse high levels of agreeableness, extraversion, openness, and low levels of neuroticism [24]. Prosocial behavior was also found in grateful people than less grateful people. They are more helpful, supportive, forgiving, and empathic toward others [24].

Broaden and build theory [30] (Fredrickson, 2001) explains that positive emotions such as happiness can broaden the repertoires of thought-action momentarily and build enduring personal resources. In addition, according to Frederickson (2001) [30] broaden the gratitude can boost the creative reciprocity and form a psychological, social, spiritual and positive resources. All of it would directly increase the possibility of happiness.

Past studies have also found that gratitude has strong relationship to psychological health and positive social functioning [24]-[25]. Watkins et al. (2003) [25] has also found that grateful people tend to experience greater positive emotions, such as more frequent joy, happiness, and hope, as well as fewer negative emotions. The regular experience of positive emotions can make people healthier and more resilient [30]. In addition, Watkins (2004) [25] describes several mechanisms to explain how gratitude affects happiness. First, gratitude when receiving "something special" will increase the feeling of happiness, second, gratitude alone both bring a sense of satisfaction within the individual, third grateful behavior itself can serve as a positive coping for person when faced with a problem in his life, fourth, grateful behavior will increase the accessibility and recollection of pleasant life events. Last, grateful behavior will reduce the likelihood of depressed mood on the person.

Contrarily, forgiveness does not show a significant relationship with wellbeing. This result does not confirm several past studies. Worthington, Witvliet, Pietrini, \& Miller (2007) [12] found that forgiveness has 
a relationship with wellbeing. Witvliet, Ludwig, \& VanderLaan (2001) [11] found forgiveness can reduce negative emotions, reduce stress and improve the physiological status of physical health. Emotional forgiveness can replace negative emotions with positive emotions. Emotional forgiveness can also change the psychophysiological more positive on person's health and well-being.

\section{CONCLUSION}

This study recommend to related parties such as teachers or lecturer, that they should encourage, and improve students' grateful behavior. Grateful behavior has several positive benefits when it is implemented and used in everyday situation, because students cannot be separated from the problem of life. Grateful behavior can be used as a positive coping when dealing with problems of daily life. Nonetheless, present study has a limitation, one of it is the sample size is small, so the results of this study may not be generalized to other sample.

\section{REFERENCES}

[1] Csikszentmihalyi, M., \& Hunter, J., "Happiness in everyday life: The uses of experience sampling”, Journal of Happiness Studies, vol. 4, pp. 185-199, 2003. doi:10.1023/A:1024409732742.

[2] Park, N., Peterson, C., "Character strengths and happiness among young children: Content analysis of parental descriptions”, Journal of Happiness Studies, vol. 7, pp. 323-341, 2006. doi:10.1007/s10902-005-3648-6.

[3] Peterson, C., Ruch, W., Beermann, U., Park, N., Seligman, MEP., "Strengths of character, orientations to happiness, and life sat- isfaction”, The Journal of Positive Psychology, vol. 2, pp. 149-156, 2007. doi:10.1080/17439760701228938.

[4] Fredrickson, BL., "Positive Emotions Broaden and Build”, Advances in Experimental Social Psychology, vol. 47, pp. 1-53, 2013.

[5] Moore, BS., Clyburn, A., Underwood, B., “The role of affect in delay of gratification”, Child Development, vol. 47, pp. 273-276, 1976.

[6] Schwarz, JC., Pollack, PR., “Affect and delay of gratification”, Journal of Research in Personality, vol. 11, pp. 147164, 1977.

[7] Chan, YK., Lee, RPL., "Network size, social support and happiness in later life: A comparative study of Beijing and Hong Kong”, Journal of Happiness Studies, vol. 7, pp. 87-112, 2006.

[8] Natvig, GK., Albrektsen, G., Qvarnstrom, U., "Associations between psychosocial factors and happiness among school adolescents”, International Journal of Nursing Practice, vol. 9, pp. 166-175, 2003.

[9] North, RJ., Holahan, CJ., Moos, RH., Cronkite, RC., "Family support, family income, and happiness: A 10-year perspective”, Journal of Family Psychology, vol. 22, pp. 475-483, 2008.

[10] Baumeister, RF., Campbell, JD., Krueger, JI., Vohs, KD., "Does high self-esteem cause better performance, interpersonal success, happiness, or healthier lifestyles?”, Psychological Science in the Public Interest, vol. 4, pp. 144, 2003.

[11] Witvliet, C., Ludwig, TE., VanderLaan, KL., "Granting forgiveness or harboring grudges: Implications for emotion, physiology, and health”, Psychological Science, vol. 12, pp. 117-123, 2001.

[12] Worthington, EL., Witvliet, CVO., Pietrini, P., Miller, AJ., "Forgiveness, health, and well-being: A review of evidence for emotional versus decisional forgiveness, dispositional forgivingness, and reduced unforgiveness", Journal of Behavioral Medicine, vol. 30, pp. 291-302, 2007.

[13] Froh, JJ., Yurkewicz, C., Kashdan, TB., "Gratitude and subjective well-being in early adolescence: Examining gender differences”, Journal of Adolescence, article in press, pp. 1-18, 2008. doi:10.1016/j.adolescence.2008.06.006.

[14] Hannon, PA., Finkel, EJ., Kumashiro, M., Rusbult, CE., "The soothing effects of forgiveness on victims' and perpetrators' blood pressure”, Personal Relationships, vol. 19, pp. 279-289, 2012.

[15] Worthington, EL., "Just forgiving: How the psychology and theology of forgiveness and justice inter-relate", Journal of Psychology and Christianity, vol. 25, pp. 155-168, 2006.

[16] Maltby, J., Day, L., Barber, L., "Forgiveness and mental health variables: Interpreting the relationship using an adaptation-continuum model of personality and coping”, Personality and Individual Differences, vol. 37, pp. 16291641, 2004.

[17] Lawler, KA., Younger, JW., Piferi, RL., Billington, E., Jobe, R., Edmondson, K., Jones, WH., “A change of heart: Cardiovascular correlates of forgiveness in response to inter- personal conflict”, Journal of Behavioral Medicine, vol. 26, pp. 373- 393, 2003.

[18] Wood, AM., Joseph, S., Maltby, J., "Gratitude predict psychological wellbeing above the Big Five facets", Personality and Individual Differences, vol. 49, pp. 443-447, 2009.

[19] Worthington, EL., "More questions about forgiveness: Research agenda for 2005-2015”, In E. L. Worthington, Jr. (Ed.), Handbook of forgiveness (pp. 557-574). New York, NY: Brunner-Routledge, 2005.

[20] Worthington, EL., Sandage, SJ., Berry, JW., "Group interventions to promote forgiveness: What researchers and clinicians ought to know?”, In M. E. McCullough, K. I. Pargament, \& C. E. Thoresen (Eds.), Forgiveness: Theory, research and practice, pp. 228-253, New York, NY: Guilford, 2000. 
[21] Worthington, EL., Scherer, M., "Forgiveness is an emotion-focused coping strategy that can reduce health risks and promote health resilience: Theory, review, and hypotheses”, Psychology \& Health, vol. 19, pp. 385-405, 2004.

[22] Worthington, EL., Wade, NG., "The social psychology of unforgiveness and implications for clinical practice", Journal of Social \& Clinical Psychology, vol. 18, pp. 385-418, 1999.

[23] McCullough, ME., Witvliet, CV., "The psychology of forgiveness”, In Snyder, C. R., and Lopez, S. J. (Eds), Handbook of Positive Psychology, Oxford University Press, Oxford, pp. 446-458, 2002.

[24] McCullough, ME., Emmons, RA., Tsang, J., “The grateful disposition: A conceptual and Empirical Topography”, Journal of Personality and Social Psychology, vol/issue: 82(1), pp. 112-127, 2002.

[25] Watkins, PC., Woodward, K.,Stone, T., Kolts, RL., "Gratitude andhappiness:Developmentofa measure ofgratitude,andrelationshipswith subjectivewell-being”, Social Behavior and Personality, vol/issue: 31(5), pp. 431452, 2003.

[26] Tkach, C., Lyubomirsky, S., "How do people pursue happiness? Relating personality, happiness-increasing strategies, and well-being”, Journal of Happiness Studies, vol. 7, pp. 183-225, 2006.

[27] Totterdell, P., "Mood scores: Mood and performance in professional cricketers", British Journal of Psychology, vol/issue: 90(3), pp. 317-332, 1999.

[28] Jopp, D., Rott, C., "Adaptation in very old age: Exploring the role of resources, beliefs, and attitudes for centenarians’ happiness”, Psychology and Aging, vol. 21, pp. 266-280, 2006.

[29] Hills, P., Argyle, M., "The Oxford Happiness Questionnaire: a compact scale for the measurement of psychological well-being”, Personality and Individual Differences, vol. 33, pp. 1073-1082, 2002.

[30] Fredrickson, BL., Joiner, T., "Positive emotions trigger upward spirals toward emotional well-being”, Psychological Science, vol. 13, pp. 172-175, 2002. 